\title{
An evaluation of the dynamics of the plan to develop first-class universities and top-level research centers in Taiwan
}

\author{
Dian-fu Chang · Cheng-ta Wu • Gregory S. Ching • \\ Chia-wei Tang
}

Received: 24 October 2008/Revised: 28 December 2008/Accepted: 11 January 2009/Published online: 24 April 2009

(C) The Author(s) 2009. This article is published with open access at Springerlink.com

\begin{abstract}
The recent rise in globalization has brought forth a global wave of academic competitiveness, which has taken its strongest hold in East Asia. In order to attain world class status, Taiwan's Ministry of Education (MoE) initiated a project called Plan to Develop First-class Universities and Top-level Research Centers. The project is often coined the "Five-Years-50-Billion Project," due to the fact that the MoE will invest 50 billion New Taiwan dollars (US\$1.64 billion) in the plan over a five year span. First, the authors will attempt to investigate and analyze the difference in funding rationale and policy between the periods before and after implementation. Second, this study seeks to evaluate the plan's efficiency on an institutional level by using data envelopment analysis (DEA). Findings suggest that the current funding policy has indeed increased Taiwanese universities' levels of internationalization and global academic competitiveness. However, comparisons among those universities suggest that despite the relative degree of efficiency, more investment did not ensure better university performance. Guidelines for allocating funding should be regularly revised in order to reflect any changes in relevant conditions and in universities' overall performance and efficiency.
\end{abstract}

D.-f. Chang

National Chi Nan University, Nantou County, Taiwan

C.-t. $\mathrm{Wu}(\square)$

Graduate School of Educational Administration and Policy,

National Cheng Chi University, No. 64, Sec. 2, ZhiNan Rd,

Wenshan District, Taipei City 11605, Taiwan ROC

e-mail: chengta@nccu.edu.tw

G. S. Ching - C.-w. Tang

National Cheng Chi University, Taipei City, Taiwan
Keywords Data envelopment analysis ·

Plan to develop first-class universities and top-level research centers · Policy evaluation · Funding evaluation

\section{Introduction}

The pressure to compete internationally and to attain global recognition has become one of the major benchmarks in evaluating university performance (Mok 2003; Song and Tai 2007). Together with rising concerns about the value of money, public accountability has already changed the way higher education is governed (Welch 2004). Advanced nations, such as the UK (with its University Appropriations Committee) and the US (with its Higher Education Project Funds in the Department of Education), along with Japan and Germany, have all allocated funds to assist in the development of key universities. To boost higher education competitiveness, the California state government is planning to subsidize four inter-university research centers, amounting to US\$100 million (NT\$3.05 billion; based on US\$1 = NT\$30.5) awarded to each center over 4 years.

Likewise, countries in East Asia-driven toward the goal of enhancing their global competitiveness-have started to take serious steps in this direction. South Korea invests a total of 290 billion Korean won (NT\$8.79 billion; based on NT\$1 = KRW 33) each year to promote its 7-year Brain Korea 21 (BK21) program, with the objective of upgrading Seoul University to one of the top 100 universities in the world. More recently, the Ministry of Education, Science and Technology planned to invest 825 billion Korean won over 5 years to help foster research at universities, under a "World Class University" project announced on June 20, 2008 (MoEST 2008).

Japan has also come up with guiding principles for reforming the structure of universities, with the objective of 
turning 30 of its institutions into world-class universities and/or research centers. Based on this concern, the projectcalled Targeted Support for Creating World-Standard Research and Education Bases-was established in 2002. Its aim was to cultivate a competitive academic environment among Japanese universities by providing targeted support to the creation of world-standard research and education bases. Through these efforts, the program seeks to elevate Japanese universities to the world's highest echelons (JSPS 2008). In mainland China, in order to enhance universities' international competitiveness in a globalizing world, the Chinese government has implemented major projects, such as the 211 Project and the 985 Program, in pursuit of creating world-class universities (Mok and Chan 2001). By recognizing the increasing global competition among universities and the pressure exacted by university rankings, the Chinese government has strategically identified key national bases for humanities and social sciences research, and major national laboratories have been established to promote scientific research (Huang 2006).

In Taiwan, the government has realized that globalization has accelerated competition among universities around the world (Lo and Weng 2005; Lu 2004; MoE 2006). A series of large-scale projects were launched in order to catch up with the rest of the world's higher education systems amid the powerful trend of globalization (Song and Tai 2007). Among these projects, Plan to Develop First-class Universities and Top-level Research Centers is the project with largest competitive fund. The empirical part of this study analyzes the outcome of this project, adopted by the Taiwan Ministry of Education, in creating world-class universities and research centers. The prospective performances of the funded universities were evaluated with official data from the Department of Higher Education in Taiwan.

The following segment consists of four sections. Section 1 reviews the public funding policy of Taiwan's higher education system and the plan to develop worldclass universities and research centers. Section 2 provides a description of the research methodology, which leads to an outline of the methodological framework used in this study. Section 3 provides a discussion of the results from the data envelopment analysis (DEA), which leads to the concluding statements in Sect. 4.

\section{Literature review}

Transforming public funding policy for higher education in Taiwan

The issue of higher education funding is controversial all over the world. In Taiwan, the philosophy underlying funding policies differed greatly before and after 1985 .
Before 1985, amendments to the Law of University in 1972 and 1982 confirmed the leadership position of the government in the management of higher education. Since the number of higher education institutes (HEIs) was small, higher education was deemed a "public good," and the government financed most public HEIs and a large percentage of the funding for private HEIs (Tang 2005). The amount of funding was solely dependent on the number of students and staff at each university (Higher Education Department 2005). Since HEIs unconditionally received enough funds from the government, all they had to do was adhere to a routine budget. During this period, HEIs did not need to compete for external funding and student enrollment; concepts such as efficiency and accountability received no attention from either the government or the HEIs (Gai 2004).

From sole provider to regulator

Since the late 1980s, higher education in Taiwan has experienced tremendous expansion in terms of the number of students and the number of HEIs. The number of universities has increased dramatically, from 7 in 1950 to 164 in 2008. Among these are 100 universities, 49 colleges, and 15 junior colleges (MoE 2008). After this increase in higher education, about 1.3 million Taiwanese students were enrolled in more than a 100 universities during the academic year 2006-2007 (MoE 2008). In order to reduce the government's burden of higher education financing, the MoE has adopted a new policy to finance all national universities in Taiwan by providing only $80 \%$ of the total budget, while leaving the remaining $20 \%$ to the financial resources of individual universities. In addition, the Educational Funding System was introduced to ensure the efficient use of government funding. In the Educational Funding System, all revenues and expenditures are supervised and managed by the Board of Educational Funding with the aim of promoting the independence of HEIs and the efficiency of funding management (Tang 2004).

Policy trends: market governance and contractual relations between the government and HEIs

The development of higher education has an influence on the allocation of educational resources (MOE 2006). Previously, resources were allocated equally without incorporating the mechanisms of competition and assessment. While the population of students in higher education is growing rapidly, resources are unable to respond in kind. Insufficient resources have led to the stagnation of teaching and research levels at universities, making improvement almost impossible. The main disadvantage of the ordinary funding method was an excessive dispersal of resources, 
which failed to encourage HEIs to engage in competition according to their specialties, and which influenced the growth of academic competitiveness (Higher Education Department 2005).

The force of marketization was increasingly predominant in the public funding policy in Taiwan; one main piece of evidence regarding this trend can be gleaned from the contractual relationship between the government and HEIs (Sporn 2006 as cited in Tang 2004). In pursuit of educational excellence and global competitiveness, the MoE launched a series of competitive funding projects in 2000 in order to supplement the ordinary funding scheme. These included Program for Promoting the Academic Excellence of Universities, Program to Promote the International Competitiveness of Universities, Research University Integration Project, Program for Improving Research University Infrastructures, Program for Expanding Overseas Student Recruitment, Plan to Develop World-Class Universities, and Program for Rewarding the Teaching Excellence of Universities. Competitive funding was attached to each of these projects; then funds were allocated under the philosophy of "pursuit of excellence." The number of recipients was rather small, while the average amount of funding allocated to each recipient was quite large. Among these projects, the Plan to Develop First-Class Universities and Top-Level Research Centers drew the most attention from both HEIs and the government. The total funding for that project was the largest ever, and only 12 top universities out of 164 institutions were its recipients.

Plan to develop first-class universities and top-level research centers

In virtue of the already limited resources that were further diminished by the growth in higher education and its attendant pursuit of excellence, MoE was aware of that instead of assisting all HEIs; they needed to invest extra funding in selected "promising" institutions. Based on this concern, Plan to Develop First-class Universities and Top-level Research Centers was put forth according to suggestions made in the Higher Education Macroscopic Planning Report prepared by the Higher Education Macroscopic Planning Committee, which proposed strategies that would raise the level of competitiveness among institutions of higher education. The plan was comprised of two sub-plans: Plan to Develop First-class Universities and Plan to Develop Top-level Research Centers. The purpose of these plans was to assist universities through competitive funding and thus improve their worldwide academic competitiveness. The main objectives of this project can be summarized as follows (MoE 2006):
(1) In 10 years, at least one university will become one of the world's top 100 universities. In 15-20 years, that university will become one of the world's top 50 universities, with several research centers in that university having the potential of becoming some of the world's Top-level research centers.

(2) At least 10 outstanding fields, departments, or research centers will become Asia's first-class areas within 5 years. In 10 years, these will have the potential of becoming among the top 50 in their respective fields.

(3) The R\&D quality of universities will be raised, as will their influence on and visibility in international academic circles.

(4) Distinguished foreign teaching and research individuals will be recruited to train students in cutting-edge industries.

(5) Substantive exchange and cooperation will be established among transnational academic organizations.

Project application and review procedure

This project targeted the promotion of excellence in "promising" HEIs. The selection of recipients required HEIs to submit a written preliminary project proposal for review. After a list of passing HEIs was posted, each school briefed the review committee. If several schools were going to consolidate, they had to submit a joint consolidation proposal. The items required in each project proposal included current status and self-assessment of the school's competitive edge, year-by-year assessment indicators, strategies to achieve objectives, and financial planning with year-by-year funding requirements.

Proposal reviews were held twice, in 2005 and 2007. The review committee consisted of highly esteemed academics and experts, from both Taiwan and abroad, who were responsible for identifying the HEIs that had the potential to become first-class in their respective fields. The review standards and criteria for Plan to Develop Firstclass Universities included the management and organizational operating system of the school as well as the school infrastructure, staffing quality, and research performance (see Appendix A for details). The review standards and criteria for Plan to Develop Top-level Research Centers included the quality of teaching and research personnel; steps taken to recruit distinguished individuals; the rise in teaching performance, creative mechanisms, and methods of academic research; the methods used to cooperate with domestic and foreign schools, research institutions, and results; the school's overall support resources; and qualitative indicators designated by the review committee (MoE 2006). In the first round of review, beginning in 2005, the 
MoE selected only two universities as the recipients of Plan to Develop First-class Universities. Besides these, $10 \mathrm{key}$ universities or research centers were also selected for Plan to Develop Top-level Research Centers and were assisted in the development of superior fields.

\section{Funding scheme}

MoE has admitted that in order to develop first-class universities, there must be an increase in the input of educational resources. Seoul University, for example, moved into the world's top 100 within 7 years with an annual funding of $\$ 5.8 \mathrm{bn}$. A budget of $\$ 100 \mathrm{bn}$ for a period of 10 years was allocated to this plan, which raised the unit student cost to about US $\$ 10,000$. Funding for top-level research centers depends on the number of firstclass universities that are subsidized with a maximum of $\$ 65 \mathrm{bn}$. Recipients were required to form a consultation committee comprised of outstanding academics from Taiwan and abroad. This committee was to offer suggestions to improve the recipients' implementation plans (Table 1).

The funding offered by the plan aims to improve teaching and research environments, encourage international academic exchanges, employ off-payroll personnel, and pay for the non-statutory expenses of on-payroll personnel, including well-known academics, experts, technicians, and postdoctoral researchers. Maximum pay for the duration of employment may be the same as salaries received overseas in order to raise teaching and research levels. MoE did not set detailed requirements or limitations on how recipients should use their funding; however, recipients' executive plan and ongoing performance were included in annual evaluation reports, which were the basis of further funding appropriation in later years.

\section{Methodology}

The main purpose of this study was to evaluate the effects and outcomes of the project called Plan to Develop Firstclass Universities and Top-level Research Centers, which has brought in selected universities since its implementation in 2005. Descriptive statistics and the DEA method were adopted during data analysis to weigh the relative performance of 12 recipient universities in Taiwan between 2005 and 2007. The analysis asked and answered the following research questions:

(1) Did the project promote the global competitiveness of selected recipients in terms of research and development activities and internationalization?

(2) Among the 12 recipients, which universities are comparatively efficient and inefficient?

(3) If greater overall efficiency is predicted, what is the top-priority operation for the inefficient Decision Making Unit (DMU)?

Advantages and applications of DEA methods

Various techniques and approaches have been used for efficiency measurement. A crucial distinction among existing approaches is the difference between parametric and nonparametric methods, with the DEA methodology ranked as one of the most popular techniques. Its popularity could be due to some important advantages that it has over the econometric approach to efficiency measurement (Sengupta and Sfeir 1988). First, it is nonparametric, so there is no need to make assumptions concerning inputs and outputs. Second, DEA permits the construction of a frontier over the data, which provides an approach to calculating the efficiency gap between each individual DMU and the most productive DMU, and makes possible the

Table 1 Year-by-year budgets for Plan to Develop First-class Universities

\begin{tabular}{|c|c|c|c|c|c|c|}
\hline \multicolumn{7}{|c|}{ Year-by-year budgets for various sub-plans of the plan $(\$ 100 \mathrm{~m})$} \\
\hline Phase 1 & 2005 & 2006 & 2007 & 2008 & 2009 & Total \\
\hline Total budget & 100 & 100 & 100 & 100 & 100 & 500 \\
\hline First-class universities & $35-60$ & $35-60$ & $35-60$ & $35-60$ & $35-60$ & $175-300$ \\
\hline Top-level research centers & $40-65$ & $40-65$ & $40-65$ & $40-65$ & $40-65$ & $200-325$ \\
\hline Phase 2 & 2010 & 2011 & 2012 & 2013 & 2014 & Total \\
\hline Total budget & 100 & 100 & 100 & 100 & 100 & 500 \\
\hline First-class universities & $35-60$ & $35-60$ & $35-60$ & $35-60$ & $35-60$ & $175-300$ \\
\hline Top-level research Centers & $40-65$ & $40-65$ & $40-65$ & $40-65$ & $40-65$ & $200-325$ \\
\hline
\end{tabular}

Source: Plan to Develop First-class Universities and Top-level Research Centers, MoE 2006. Retrieved July 3, 2008, from http://english.MoE.gov.tw/ct.asp?xItem=7131\&ctNode=505\&mp=1 
pinpointing of deficiency sources and amounts for each DMU (Haji 2006; Malano et al. 2004). In addition, it allows researchers to simultaneously include multiple inputs and outputs in one model of a DMU's efficiency. Furthermore, the analytical power of DEA is not affected by a smaller sample size, as long as the number of inputs is smaller than that sample size (Thiam et al. 2001).

Several studies have used DEA and DEA-based Malmquist productivity indices to examine relative efficiency and efficiency changes in the higher education system (Abbott and Doucouliagos 2002; Arcelus and Coleman 1997; Breu and Raab 1994; Johnes 2006; Sinuany-Stern et al. 1994). The greatest distinction between higher education and primary or secondary education is the multi-dimensional nature of its inputs and outputs. Due to this distinction, DEA, which can handle both multiple inputs and multiple outputs, is an attractive tool of analysis for measuring the performance of HEIs (Johnes 2006). Moreover, one characteristic of DEA is its freedom from the limitation of small sample sizes. While the number of the recipients of the funding project (IMUs) was only 12, the DEA method prevented statistical problems in the application of other parametric methods. Due to these concerns, this study proffered DEA as the most suitable method for further data analysis.

\section{An overview of DEA method}

Data envelopment analysis has developed considerably since its inception by Farrell in 1957. It is a powerful method widely used in the evaluation of the performance of DMUs. DEA evaluates efficiency, i.e., the relationship between inputs and outputs. It thereby determines overall efficiency, which consists of both purely technical efficiency and allocative efficiency. The "classical" efficiency measure of Farrell (1957 as cited in Charnes et al. 1978) was generalized by Charnes et al. (1978) as a response to the need to evaluate the efficiency of not-for-profit organizations. They introduced the ratio definition of efficiency, which generalizes the single-output to single-input ratio definition used by Farrell (1957) to multiple outputs and inputs. In this model, DMU efficiency measurement is defined as each organization's mathematical position as it relates to the "frontier" of best performance, which is established by the ratio of weighted sum of outputs to weighted sum of inputs.

$\max \frac{\text { sum of weighted outputs }}{\text { sum of weighted inputs }}$.

Each DMU uses $m$ inputs and $s$ outputs. $\mathrm{DMU}_{j}$ $(j=1, \ldots, n)$ takes the quantity $X_{i j}$ of input $i$ and the quantity $Y_{r j}$ of output $r$. This means that $X_{i k} \geq 0$ and $Y_{r j} \geq 0$, and each DMU have at least one positive input and output value. Let $u_{r}$ and $v_{i}$ be the weight of output $r$ and of input $i$, respectively, $Y_{r k}$ and $X_{i k}$ being the observed values of the DMU $k$ under evaluation. The weights are fixed at the beginning and are calculated within the analysis. The mathematical model for a DMU $k$, is defined by:

$\operatorname{Max} E_{k}=\frac{\sum_{r=1}^{s} u_{r} Y_{r k}}{\sum_{i=1}^{m} v_{i} X_{i k}}$

Subject to $\begin{aligned} \frac{\sum_{r=1}^{s} u_{r} Y_{r j}}{\sum_{i=1}^{m} v_{i} X_{i j}} \leq 1, \quad j & =1,2, \ldots, n, \quad u_{r}, v_{i} \geq \varepsilon, \quad r \\ & =1,2, \ldots, s, \quad i \\ & =1,2, \ldots, m .\end{aligned}$

This model focuses on proportional improvement and reduction potentials. $\theta$ is the proportional decrease in inputs possible for the $k$-th DMU. $\varepsilon$ is a very small positive constant. An efficiency score of $\theta$ (the reduction factor of the inputs) will be assigned to its respective DMU. For $\theta<1$, the DMU is inefficient (Leitner et al. 2005).

\section{Data collection}

To answer the research questions of this study, descriptive statistics and the DEA method were adopted in data analysis. For descriptive statistics, survey data from the higher education department and the MoE were adopted, which projected an overview of the outcome of this project after two years' implementation. In order to gain further insight into the efficiency of funding recipients, the DEA method was adopted. One input and six outputs have been incorporated into the CCR model.

Input measurement and data

The sole input of this project was monetary funding. According to MoE (2006), in 2005, NT\$100 million was allocated for 12 recipients. Funding received by schools in 2005 (NT\$100 million) is shown in Fig. 2 (Table 2).

Output measures and data

According to the MoE (2006), the aim of the project was to enhance the performance of selected universities in terms of R\&D quality and internationalization. In consideration of this objective and of the availability of related data, the outputs included in this study's DEA model were number of degree-seeking international students, number of international exchange students, number of international 
Table 2 Funding received by schools in 2005 (NT\$100 million)

\begin{tabular}{lll}
\hline Code & School & Amount \\
\hline 1 & National Taiwan University $^{\mathrm{a}}$ & 30 \\
2 & National Cheng Kung University $^{\mathrm{a}}$ & 17 \\
3 & National Tsing Hua University $^{\mathrm{a}}$ & 10 \\
4 & National Chiao Tung University $^{\mathrm{a}}$ & 8 \\
5 & National Central University $^{\mathrm{b}}$ & 6 \\
6 & National Sun Yat-Sen University $^{\mathrm{b}}$ & 6 \\
7 & National Yang Ming University $^{\mathrm{b}}$ & 6 \\
8 & National Chung Hsing University $^{\mathrm{b}}$ & 6 \\
9 & National Taiwan University of Science and $^{\mathrm{T}}$ & 6 \\
10 & Technology $^{\mathrm{b}}$ & \\
11 & National Chengchi University $^{\mathrm{c}}$ & 3 \\
12 & Chang Gung University $^{\mathrm{c}}$ & 3 \\
\hline
\end{tabular}

Source: Plan to Develop First-class Universities and Top-level Research Centers, MoE, 2006. Retrieved July 3, 2008, from http://english.MoE.gov.tw/ct.asp?xItem $=7131 \& \mathrm{ctNode}=505 \& \mathrm{mp}=1$

Note: NT\$100 million approximately equal to US\$3.28 million (based on US\$1 = NT\$30.5)

a Schools that received funding of NT $\$ 800$ million and above (consider as group A schools)

b Schools that received funding of NT\$600 million (consider as group B schools)

${ }^{c}$ Schools that received funding of NT\$300 million (consider as group C schools)

collaborations, number of visiting international scholars, number of articles published in international journals that are indexed in the SCI, SSCI, and A\&HCI databases, and national scientific and educational collaboration expenditures in the form of new Taiwan dollars.

\section{Results and discussion}

The development of first-class universities and top-level research centers requires a large investment of time and money, and yearly performance evaluation is crucial in order for the recipients to move in the right direction and to be accountable for their actions (MoE 2006). This section includes a glimpse at the overall performance of the 12 recipients, 1 year after this project launched. The end of this section will address information that compares efficient DMUs with inefficient DMUs.

Statistical analysis: before and after project implementation

Figures 1, 2, 3, 4, 5, and 6 show the growth rates of selected output measures in 2006. Both Chang Gung and Yuan Ze Universities experienced an increase in the growth rate of degree-seeking international students (see Fig. 1), while

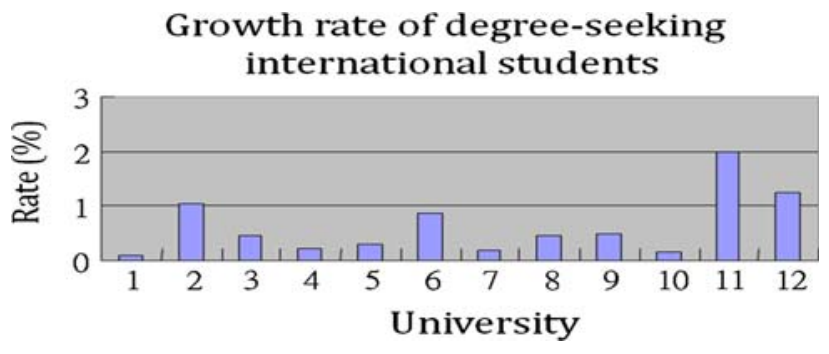

Fig. 1 Growth rate of degree-seeking international students

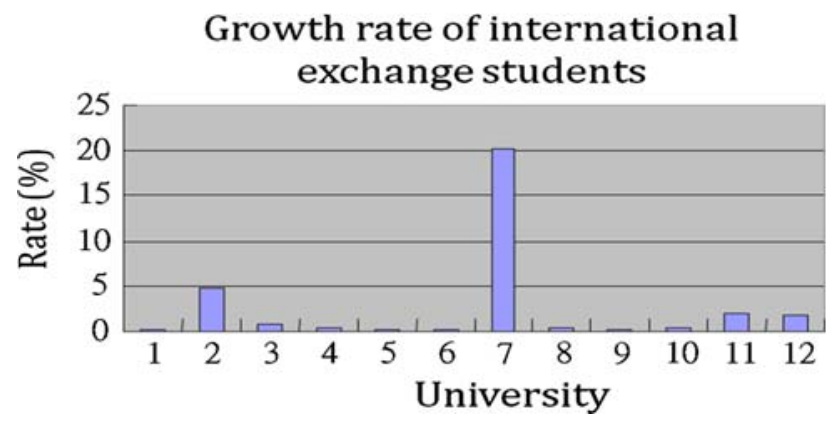

Fig. 2 Growth rate of international exchange students



Fig. 3 Growth rate of international collaborations

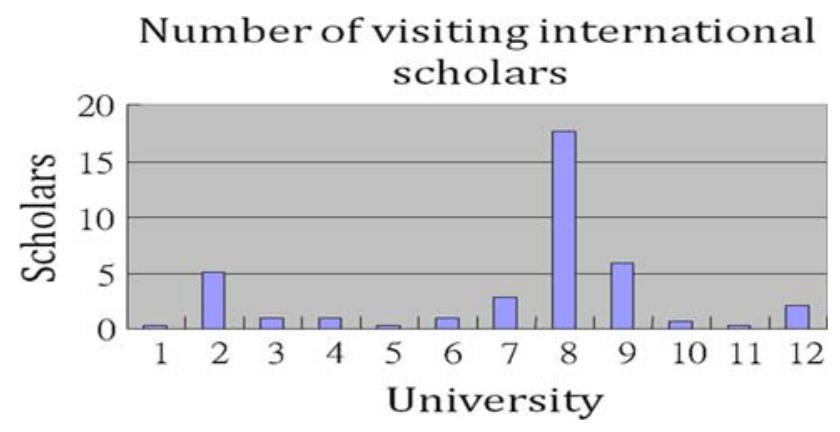

Fig. 4 Number of visiting international scholars

Yang Ming University experienced an increase in the growth rate of international exchange students (see Fig. 2). As was discovered after further analysis of these schools' internationalization strategies, some of their policies included scholarships for foreign students, dual bachelor's and master's degree programs, and foreign language courses. 
Growth rate of articles in international journals $(\mathrm{SCI}+\mathrm{SSCI}+\mathrm{A} \& \mathrm{HCI})$

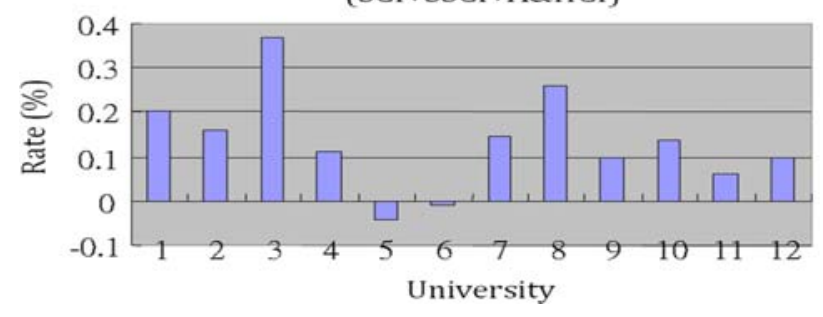

Fig. 5 Growth rate of articles in international journals

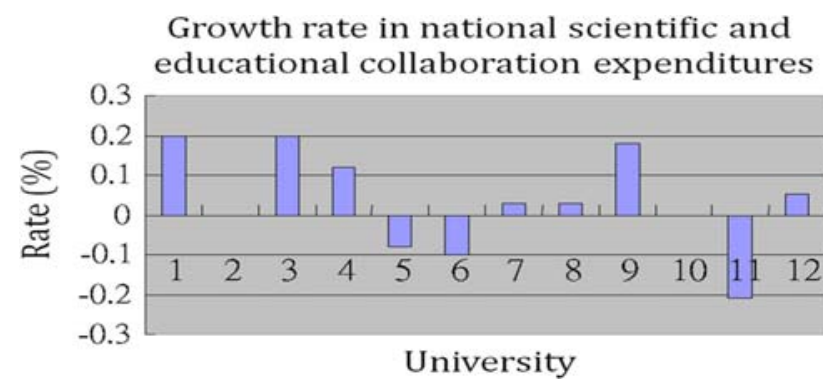

Fig. 6 Growth rate in national scientific and educational collaboration expenditures

As for international collaboration, most of the universities experienced large growth rates during the 1-year period (see Fig. 3). Common strategies included establishing international sister schools, organizing international research teams, hosting international academic conferences, and making flexible degree programs available. Chung Hsing University showed particularly outstanding performance in the number of visiting international scholars (see Fig. 4), and adopted policies such as flexible compensation in order to attract international and worldclass scholars and to create scholarship opportunities for foreign faculty.

An overall similarity among the above-mentioned schools was the existence of an international education exchange center that handles all of the university's internationalization tasks. This setup not only increases the visibility of the university in the international arena, but also maintains good relations with foreign institutions and students. It helps better facilitate the activities of inbound foreign students and outbound local students. It also helps coordinate exchange opportunities and provides an array of services that prepare students for whatever challenges they may face when coming to Taiwan to study or when leaving Taiwan to study abroad.

With regard to publications in foreign international journals, most schools showed an increased growth rate; Tsing Hua, Chung Hsing, and National Taiwan Universities showed the highest increases (see Fig. 5). These schools adopted policies such as funding assistance for research projects and additional monetary incentives for each publication in an international journal, especially those indexed in SCI/SSCI/A\&HCI. These have sparked an increase in the number of Taiwanese scholars in the international academe.

In general, it is suggested that substantial progress was made within the year that the project was launched. Belowzero-growth rates only appeared in few of the universities on two output measures, which are the number of articles published in international journals and the national scientific and educational collaboration expenditures (see Figs. 5, 6). As for the former, the rate of decline was rather slight. One possible reason that some of the universities gained fewer opportunities for national scientific and educational collaboration expenditures than others did was that the total number of such opportunities was usually constant. If one of the universities acquired money through cooperation, it created a loss for others. In sum, although it was only the first year of the MoE's project, 12 universities experienced immediate and apparent improvement in many aspects of internationalization and R\&D development.

The empirical results of the DEA analysis provided valuable diagnostic information. First, based on the six output measures and the single input (total amount of funding received), we calculated the efficiency score for 12 universities with reference to other efficient DMUs. Moreover, the surplus analysis provided suggestions for managerial auditing. As Table 3 indicates, five universities were relatively efficient; these are marked with an efficiency score of 100 , which implies that their resource utilization was comparatively efficient. That score represents the percent of outputs, one DMU produced in comparison with efficient DMUs when the same efficiency level was predicted. Taiwan University is a good example: its efficiency score was 71.44, which shows that it attained $71.44 \%$ efficiency as compared with the efficient DMUs. That is to say, Taiwan University only produced $71.44 \%$ of the output that efficient universities produced with the same level of input.

To further investigate the differences among the five efficient universities, the frequency in the reference set was also included in our analysis. The frequency with which a DMU was identified as reference of other DMUs indicated the degree of robustness of that DMU compared to the other four efficient DMUs. The higher the frequency was, the more robust the DMU was. It was found that the most robustly efficient DMUs were Central University, Chengchi University, and Chang Gung University. Accordingly, this study assigned a rank to each DMU, shown in the right-hand column of Table 3.

It is significant that Chengchi University and Chang Gung University received the least amount of funding from the MoE and still outperformed other universities that 
Table 3 Relative efficiency of DMUs

\begin{tabular}{lcccc}
\hline DMU & & \multirow{2}{*}{ Efficiency score } & Reference \\
\cline { 1 - 2 } Frequency & Rank & & 9 \\
\cline { 1 - 2 } 1. National Taiwan University & 71.44 & 0 & 10 \\
2. National Cheng Kung University & 67.78 & 0 & 8 \\
3. National Tsing Hua University & 81.33 & 3 & 7 \\
4. National Chiao Tung University & 88.35 & 3 & 1 \\
5. National Central University & 100 & 7 & 11 \\
6. National Sun Yat-Sen University & 65.52 & 0 & 12 \\
7. National Yang Ming University & 56.41 & 0 & 4 \\
8. National Chung Hsing University & 100 & 6 & 6 \\
9. National Taiwan University of Science \& Technology & 92.95 & 0 & 1 \\
10. National Chengchi University & 100 & 7 & 1 \\
11. Chang Gung University & 100 & 7 & 5 \\
12. Yuan Ze University & 100 & 2 &
\end{tabular}

received much higher budgets. Similarly, the other two efficient DMUs (Yuan Ze University and Chung Hsing University) received only NT\$600 million, while most of the DMUs with lower rankings received more funding from the MoE. These observations suggest the possibility that with limited recourses, universities tended to use funding carefully and thus more precisely reach their anticipated development goal. On the other hand, more input did not ensure better output, a phenomenon that might be caused by deterioration through overinvestment or misuse of budgets.

The seven inefficient universities all had efficiency scores of $<100$. Table 4 shows in what output variable and to what extent inefficient universities can improve their efficiency, in relation to the efficient DMUs. Since the model adopted by this study was output oriented, the only information uncovered was the number of outputs that could be added for efficiency improvement; thus, the value for the row called "total amount of funding received" is zero. The values in Table 4 show how much more output one university must create in order to become an efficient DMU, in correspondence with the amount of input (findings) the institution receives from MoE.

If Sun Yat-Sen University (Univ. 6) aims to be efficient, it would have to raise its outputs for the number of degreeseeking international students by 40.77 units. Likewise, an increase of 56.96 units is needed for the number of international exchange students; 6.66 units for the number of international collaborations; 226.64 units for the number for visiting international scholars; 392.72 units for the number of articles in international journals; and 1.46 units for the national scientific and educational collaboration expenditures (see Table 4).

Similarly, it follows that if Yang Ming University (Univ. 7) aims to be efficient; it would have to raise its outputs for the number of degree-seeking international students by 21.63 units. Likewise, an increase of 49.45 units for the number of international exchange students; 6.95 units for the number of international collaborations; 98.12 units for the number for visiting international scholars; 690.71 units for the number of articles in international journals; and 1.63 units for the national scientific and educational collaboration expenditures (see Table 4).

\section{Conclusion}

With the recent rise in globalization and the increasing trend toward placing importance on university rankings, governments worldwide have started to focus on developing first-class universities. This study focused on Taiwan's experience with the project Plan to Develop First-class Universities and Top-level Research Centers. DEA was utilized in order to analyze the comparative performance of the 12 universities involved in the project. Data were gathered from before and after project implementation. The results indicate that even though this project had only been implemented for a single year, all the universities involved showed tremendous increase in the growth rates of their R\&D performance and their internationalization progress. Although some universities, such as National Chengchi University and Chang Gung University, received much less funding from the MoE than others did, they managed to outperform other universities that received much more. Similarly, two of the other efficient DMUs (Yuan Ze University and Chung Hsing University) received only NT\$600 million, while most DMUs with lower rankings received more funding from the MoE. This suggests the possibility that, due to limited recourses, universities tend to use their funding carefully and thus rapidly reach their 
prospective development goal. On the other hand, more input did not ensure better output, which might be cause by deterioration due to the overinvestment or misuse of budgets. Further longitudinal studies are necessary in order to attain a broader view of the whole project. An additional analysis of the factors behind the strategies used by those universities that performed best are also encouraged.

Open Access This article is distributed under the terms of the Creative Commons Attribution Noncommercial License which permits any noncommercial use, distribution, and reproduction in any medium, provided the original author(s) and source are credited.

\section{Appendix A: review standards and criteria}

1. The management and organizational operating system of the school:

a. Letter of consent to agree to become a legal entity is raised at school affairs meeting with written plan prepared.

b. Merger of two schools requires approval by school affairs meeting and preparation of implementation plan.

c. Management of school budget: Allocation of funds and adequate of use of public and private sector resources. That is, establishing the school's independent funds review mechanism and reasonable self-financing percentage.

d. Results of recruiting outstanding individuals (domestic and foreign teachers, students, and research personnel) and relevant support strategy that includes flexible salaries and employment of personnel.

e. Incorporating school-wide or inter-school human resources, organizational operation administrative infrastructure that includes reform of administrative organization (including department elimination mechanism), mechanism to evaluate and eliminate teachers and research personnel.

f. Mechanism and method to raise teaching performance and creativity of academic research that includes strategies for promoting scientific and technological R\&D by industry and academia, developing humanistic characteristics, and promoting general knowledge education.

2. School infrastructure:

a. Improve libraries, instruments and equipment that include library collections, collection of characteristic books, web exchange facilities, instruments and equipment, and establishment of friendly campus environment. 
b. Construction of classrooms and dormitories that include e-teaching equipment, dormitory for academics, housing for international students, and percentage of student dormitory supply.

c. Construction of research equipment that includes research rooms for teachers, research rooms for graduate students, and logistical resources.

3. Results of raising teaching and research performance by the school:

a. Teacher quality: Percentage of professors and assistant professors, percentage of teachers with doctoral qualifications, number of professor having won domestic and foreign awards-Nobel Prize, key international associations, academicians, or awards.

b. Through inter-school consolidation, outstanding academic fields within the school reach the standards of world's first-class universities.

c. Number of papers issued on and cited from wellknown international periodicals, impact factors that include SCI, EI, SSCI, and A\&HCI.

d. Academic scale: Numbers of research projects, industry-academia projects, and intellectual property rights (including patents, technology transfers, and professional writings).

e. Teaching excellence measures: Submitting establishment of well-rounded mechanism to evaluate teaching quality, providing teachers with professional assistance (such as Faculty Development Center), teaching evaluation of outstanding teachers, mechanism to reward and eliminate teachers, process to plan programs offered by departments, and mechanism to periodically review and evaluate.

f. Raising the degree of internationalization: Submitting methods used to work with domestic and foreign schools and research organizations to jointly design curricula, establish colleges and research centers, and confer degrees and results. Such as promoting joint school system, number of foreign students admitted (international student centers), holding international symposiums, teaching English, and campus environment.

g. Student quality: Raising student unit cost and ratio of students to teachers.

h. Alumni achievements.

i. Qualitative indicators will be prepared by the above review committee formed by domestic and foreign experts and academics invited by the Executive Yuan.

\section{References}

Abbott, M., \& Doucouliagos, C. (2002). The efficiency of Australian universities: a data envelopment analysis. Economics of Education Review, 22(1), 89-97. doi:10.1016/S0272-7757(01)00068-1.

Arcelus, F. J., \& Coleman, D. F. (1997). An efficiency review of university departments. International Journal of Systems Science, 28(7), 721-729. doi:10.1080/00207729708929431.

Breu, T. M., \& Raab, R. L. (1994). Efficiency and perceived quality of the nation's Top 25 national universities and national liberal arts colleges: an application of data envelopment analysis to higher education. Socio-Economic Planning Sciences, 28(1), 3345. doi:10.1016/0038-0121(94)90023-X.

Charnes, A., Cooper, W. W., \& Rhodes, E. (1978). Measuring the efficiency of decision making units. European Journal of Operational Research, 2, 429-444. doi:10.1016/0377-2217(78) 90138-8.

Gai, C. S. (2004). An analysis of the perceived need for increasing market orientation in Taiwan's policy on higher education. Bulletin of Educational Research, 50(2), 29-51.

Haji, J. (2006). Production efficiency of smallholders' vegetabledominated mixed farming system in Eastern Ethiopia: a nonparametric approach. Journal of African Economies, 16(1), 1-27. doi:10.1093/jae/ej1044.

Higher Education Department. (2005). Plan to develop first-class universities and top-level research centers. Retrieved July 2, 2008, from http://140.111.34.116/old/175/mainstory.html.

Huang, F. T. (2006). Difference in the context of internationalization by region: China. In N. Furushiro (Ed.), Final report of developing evaluation criteria to assess the internationalization of universities (pp. 56-70). Kwansei: Osaka University.

Johnes, J. (2006). Measuring teaching efficiency in higher education: an application of data envelopment analysis to economics graduates from UK Universities. European Journal of Operational Research, 174(1), 443-456. doi:10.1016/j.ejor.2005.02.044.

JSPS. (2008). Targeted support for creating world-standard research and education bases. Retrieved July 3, 2008, from http://www.jsps.go.jp/english/e-21 coe/index.html.

Leitner, K. H., Schaffhauser-Linzatti, M., Stowasser, R., \& Wagner, K. (2005). Data envelopment analysis as method for evaluating Intellectual Capital. Journal of Intellectual Capital, 6(4), 528543. doi:10.1108/14691930510628807.

Lo, Y. W., \& Weng, F. Y. (2005). Taiwan's responses to globalization: internationalization of higher education. In K. H. Mok \& R. James (Eds.), Globalization and higher education in East Asia. Singapore: Marshall Cavendish Academic.

Lu, M. L. (2004). The blueprint and competitiveness of Taiwan's higher education. Paper presented at the Cross Strait Seminar on Review and Prospect of the Policy of University Excellence, Taipei City.

Malano, H., Burton, M., \& Makin, I. (2004). Benchmarking performance in the irrigation and drainage sector: A tool for change. Irrigation and Drainage, 53, 119-133. doi:10.1002/ird.126.

MoE. (2006). Plan to develop first-class universities and top-level research centers. Retrieved July 3, 2008, from http://english. MoE.gov.tw/ct.asp? $x$ Item $=7131 \& c t$ Node $=505 \& \mathrm{mp}=1$.

MoE. (2008). 2008 Educational statistical indicators. Retrieved May 25, 2008, from http://english.MoE.gov.tw/lp.asp?ctNode=816\& $\mathrm{CtUnit}=507 \&$ BaseDSD $=7 \& \mathrm{mp}=1$.

MoEST. (2008). Ministry Pledges 825 Billion for Research at Universities. Retrieved July 4, 2008, from http://english.mest. go.kr/main.jsp?idx $=0801010101 \&$ brd_no $=30 \& \mathrm{cp}=1 \&$ pageSize $=$ $10 \& \operatorname{srchSel}=\& \operatorname{srch} V a l=\& b r d \_$mainno $=755 \&$ mode $=$ v . 
Mok, K. H. (2003). Similar trends, diverse agendas: Higher education reforms in East Asia. Globalization, Sociology of Education, 1(2), 201-221.

Mok, K. H., \& Chan, D. (2001). Educational reforms and coping strategies under the tidal wave of marketisation: A comparative study of Hong Kong and the mainland. Comparative Education Review, 37(1), 21-41. doi:10.1080/03050060020020417.

Sengupta, J. K., \& Sfeir, R. E. (1988). Efficiency measurement by data envelopment analysis with econometric applications. Applied Economics, 20(6), 285-293. doi:10.1080/0003684880 0000042.

Sinuany-Stern, Z., Mehrez, A., \& Barboy, A. (1994). Academic departments efficiency via DEA. Computers \& Operations Research, 21(5), 543-556. doi:10.1016/0305-0548(94)90103-1.

Song, M.-M., \& Tai, H.-H. (2007). Taiwan's responses to globalization: Internationalization and questing for world class. Asia
Pacific Journal of Education, 27(3), 323-340. doi: 10.1080/02188790701594067.

Tang, Y. (2004). A study on the audit council for the national higher education institutions. Educational Review, 20, 9-32.

Tang, Y. (2005). A study on the transformation and strategy on the university finance issues - the example of internal control system. Journal of Educational Research and Development, $1(2), 61-81$

Thiam, A., Bravo-Ureta, B. E., \& Rivas, T. E. (2001). Technical efficiency in developing country agriculture: A meta analysis. Agricultural Economics, 25, 235-243. doi:10.1111/j.1574-0862. 2001.tb00204.x.

Welch, A. (2004). Accountability or accountability? Governance and university evaluation systems in an era of performativity. $C O E$ Publication Series, 11, 117-138. 